\title{
Associations of Birth Size, Gestational Age, and Adult Size with Intellectual Performance: Evidence From a Cohort of Norwegian Men
}

\author{
MARTHA G. EIDE, NINA ØYEN, ROLV SKJÆRVEN, AND TOR BJERKEDAL
}

Department of Public Health and Primary Health Care [M.G.E., N.Ø., R.S.], The Medical Birth Registry of Norway [N.Ø., R.S.], University of Bergen, N-5018 Bergen, Norway; Center for Medical Genetics and Molecular Medicine [N.Ø.], Haukeland University Hospital, N-5021 Bergen, Norway; Institute of Epidemiology [T.B.], Norwegian Armed Forces Medical Services, MEDOPS/Ullevål University Hospital, N-0015 Oslo, Norway

\begin{abstract}
The influences of prenatal and postnatal growth on intellectual performance are unclear. We examined the associations of birth size and gestational age with intellectual performance and explored whether these associations were influenced by adult body size and social factors. In this nationwide cohort study, the records of 317,761 male infants registered in the Medical Birth Registry of Norway (1967-1979) were linked to the Norwegian Conscript Service (1984-1999). The variation in intelligence test score at age 18 due to birth weight and birth length was evaluated using absolute and standardized ( $z$ scores) values. Mean intelligence score increased by gestational age, birth weight, and birth length. However, a decline in intellectual performance was observed for gestational age $>41$ wk and birth weight $>4500 \mathrm{~g}$. There was a strong interaction on intellectual performance between birth size and gestational age $(p<$ $0.0005)$. Adjusting for adult size strongly attenuated the association of birth size with intellectual performance. The overall $R^{2}$ of intellectual performance explained by birth size was $<1 \%$; however, adding adult body size and social factors to the model increased $R^{2}$ to $12 \%$. In conclusion, the association of birth size with intellectual performance was weak, but still present after adjustment for adult body size and social factors. (Pediatr Res 62: 636-642, 2007)
\end{abstract}

$I^{n}$ tellectual performance appears to be negatively associated with important health outcomes such as all-cause mortality (1-4) and cardiovascular disease (1). Developmental research has provided evidence that insults during critical periods in early life may have lifetime consequences (5). Numerous epidemiologic studies have reported that perinatal factors including birth weight, birth length, and gestational age may influence later intellectual performance, but the mechanisms for these associations are unclear (6-19). Understanding the early life influences on intellectual performance may be important for developing initiatives aimed at preventing adverse outcomes in later life.

The association between birth size and intellectual performance may be wholly or partly explained by later growth rather than perinatal factors (20) because birth size is known to be directly related to adult height (21) and a positive

Received January 12, 2007; accepted June 13, 2007.

Correspondence: Martha Gunn Eide, Ph.D., Section for Epidemiology and Medical Statistics, Department of Public Health and Primary Health Care, University of Bergen, Kalfarveien 31, N-5018 Bergen, Norway; e-mail: martha.eide@mfr.uib.no

This work was funded by the Norwegian Research Council grant no. 129248/330. correlation between adult height and intelligence has been reported $(6,10,22-25)$. To our knowledge, only one study has so far examined the independent effects of birth weight and current size on intelligence, but this study did not include gestational age (10). Furthermore, only a small number of population-based studies exists on the association between birth weight and intelligence (18), and of these studies, the largest did not adjust for socioeconomic status (26).

To assess the associations of birth weight, birth length, and gestational age with adult intellectual performance and to explore whether the associations were influenced by adult body size and social factors, we conducted a historical birth cohort study following a large sample of male infants registered in the Medical Birth Registry of Norway and linked to data registered at the Norwegian Conscript Service as well as Statistics Norway.

\section{METHODS}

Study population. In Norway, medical data on all births from 16 wk of gestation have been recorded since 1967 by the Medical Birth Registry of Norway (27). Data on general intellectual performance, height, and weight have been routinely recorded by the Norwegian Conscripts Service in all Norwegian men at the age of $18 \mathrm{y}$; only those who are permanently disabled before this age are exempt from attending $(21,28)$. Data on delivery were linked with data on intellectual performance recorded by the Norwegian Conscript Service 1984-1999, by the unique 11-digit personal identification number. In addition, we added information on the highest attained maternal educational level in 1998 from Statistics Norway (29) and on disability status from the National Health Insurance Office (30). From 1967 to 1979, 393,570 singleton liveborn infant boys were registered in the Medical Birth Registry. In this birth cohort, $8383(2.1 \%)$ died before military draft, $3788(1.0 \%)$ emigrated, $5692(1.4 \%)$ were permanently disabled, and 24,355 (6.2\%) were untraceable (21). Birth size characteristics for this cohort have been published previously (21). Analyses were restricted to conscripts with data on intelligence testing and maternal educational level. Data on intellectual performance was missing for 18,979 of the drafted men, and another 14,612 men were excluded due to missing data on maternal educational level, thus excluding 33,591 (8.5\%) men. Consequently, 317,761 births (80.7\% of the birth cohort) were left for analysis.

Variables. Intellectual performance was measured by a 53-min standardized group intelligence test, which was developed in 1953 for the Norwegian draft board and revised in 1962. The revised version was used throughout the study period. The test included time-limited subtests organized by increasing difficulty covering three categories of items: verbal analogues, number series (calculation) and geometric figures (an abbreviated version of Raven's Progressive Matrices) (31), comprising a total of 120 questions. All conscripts received standard instructions before the tests. These tests are highly correlated with the Wechsler Adult Intelligence Scale $(r=0.73)(28,31,32)$. The performance is reported in nine standard scores; i.e. single-digit standard 
scores (with values from 1 to 9) based on the normal distribution in 1962 with a mean of 5.0 and SD of 1.96 . The overall mean score was 5.20 and slightly higher than the standardized mean (33), which is in accordance with the gain in intellectual performance tests during the time period (28). A low score was defined as $\leq 3$, corresponding to the 16th percentile of the distribution.

Data on birth weight $(\mathrm{g})$, birth length $(\mathrm{cm})$, gestational age (weeks), and year of birth, as well as data on the mother at the time of birth [age (years), marital status (married or unmarried), and parity (number of previous births, including stillbirths)] were obtained from the Medical Birth Registry. Data on birth weight, birth length, and gestational age were missing for $415(0.1 \%$ of the study cohort), $3532(1.1 \%)$, and 10,570 (2.8\%) births, respectively. Data on year of birth, maternal age, marital status, and parity were complete. Birth weight was categorized as $<1500 \mathrm{~g}, 1500-4999 \mathrm{~g}$ in 500-g categories, and $\geq 5000 \mathrm{~g}$. The gestational age-specific $z$ score (SD above or below the mean) of birth weight was calculated using Norwegian population standards (34), and the $z$ score of birth length was calculated based on the same material. $z$ Scores were categorized as $\leq-3.00,-2.99-2.00,-1.99-0.50,-0.49-$ $0.50,0.51-2.00,2.01-3.00$, and $>3.00$. Gestational age was estimated from the reported last menstrual period and analyzed as completed weeks of gestation. Preterm birth was defined as gestational age $<37 \mathrm{wk}, 37-41 \mathrm{wk}$ as term, and 42-44 wk as postterm. Maternal educational level (completed years) was categorized into low ( $\leq 10 \mathrm{y})$, medium (11-14 y), or high ( $\geq 14 \mathrm{y})$.

Data on adult height $(\mathrm{cm})$ and weight $(\mathrm{kg})$ were missing for 400 and 636 men, respectively. Height was analyzed as a continuous variable $(1-\mathrm{cm}$ increments). Quintiles and $z$ scores for height were calculated based on data from the study cohort. We categorized body mass index (BMI), i.e. weight $(\mathrm{kg}) /$ height $\left(\mathrm{m}^{2}\right)$, as $<18.5,18.5-24.9,25.0-29.9,30.0-39.9$, and $\geq 40.0$, consistent with the cutoff points proposed by the World Health Organization (35).

Statistics. The relationship between birth size and mean intelligence test scores was explored by stratification and analysis of variance (crude and adjusted analyses); comparisons were expressed as mean differences with 95\% confidence intervals (CIs) (Tables 1 and 2). For models in Table 2, all independent variables except height were treated as categorical. Because the relationship between height and intellectual performance is not purely linear (22), height was included with both linear and quadratic regression terms.

In Table 3, we applied the analytic strategy suggested by Lucas et al. (20) using $z$ scores and adjusting for later size to interpret the relative importance of early and later body size; however, we emphasized the importance of birth characteristics. $R^{2}$ was used to quantify the variance in intellectual performance. We used standard analysis of variance models for these analyses. We excluded the quadratic height-term because this did not contribute to the $R^{2}$ estimation. $z$ Scores with values outside \pm 4 SD were excluded.

For dichotomous outcomes (Table 4), crude odds ratios (ORs) were calculated, and logistic regression analysis was used to adjust for potential confounding. Interactions were evaluated in stratified analyses and with specific interaction terms in the general linear or logistic models.

In all analyses, maternal age, parity, maternal education, and BMI were treated as categorical (indicator) variables. SPSS software (version 11.0, SPSS, Chicago, IL) was used for the statistical analyses.

The Regional Committee for Medical Research Ethics, the Norwegian Board of Health, and the Norwegian Data Inspectorate approved the study.

\section{RESULTS}

In the study cohort, mean weight and length at birth was $3586 \mathrm{~g}(\mathrm{SD}=537)$ and $51.0 \mathrm{~cm}(\mathrm{SD}=2.2)$. Mean gestational age was $39.9 \mathrm{wk}(\mathrm{SD}=1.9)$ with $4.5 \%$ preterm, $80.3 \%$ term, and $15.2 \%$ postterm births. At conscription, mean height was 179.9 $\mathrm{cm}(\mathrm{SD}=6.5)$, and mean BMI was $22.3 \mathrm{~kg} / \mathrm{m}^{2}(\mathrm{SD}=3.1)$. Mean age was 18.7 y $(\mathrm{SD}=0.7)$ with $95.3 \%$ aged $18-19 \mathrm{y}$.

Figure 1 presents the relationship between gestational age, birth size, and mean intelligence test score. Mean score increased with increasing gestational age from 28 wk (SD = $4.40)$ to $40-41 \mathrm{wk}(\mathrm{SD}=5.27)$, but decreased thereafter for the highest gestational ages (5.10 at $44 \mathrm{wk}$ ) (Fig. 1A). Figure $1 B$ and $C$ show the relationship between adult intellectual performance and weight and length at birth, respectively, stratified by gestational age. There was a positive association for term births between adult intellectual performance and birth weight (Fig. 1B), as well as birth length (Fig. 1C), but
Table 1. Mean intelligence test scores with $95 \%$ CI among 317,761 drafted males by birth and maternal characteristics

\begin{tabular}{|c|c|c|c|}
\hline $\begin{array}{l}\text { Birth and maternal } \\
\text { characteristics }\end{array}$ & $n$ & $\begin{array}{l}\text { Mean intelligence } \\
\text { test score }(\mathrm{SD})^{*}\end{array}$ & $95 \% \mathrm{CI}$ \\
\hline \multicolumn{4}{|l|}{ Maternal age, ył } \\
\hline$<20$ & 23,464 & $4.77(1.73)$ & $4.75-4.79$ \\
\hline $20-24$ & 112,895 & $5.09(1.79)$ & $5.08-5.10$ \\
\hline $25-29$ & 106,358 & $5.36(1.82)$ & $5.35-5.37$ \\
\hline $30-34$ & 50,455 & $5.37(1.83)$ & $5.35-5.39$ \\
\hline$\geq 35$ & 24,589 & $5.29(1.84)$ & $5.27-5.31$ \\
\hline Total & 317,761 & & \\
\hline \multicolumn{4}{|l|}{ Parity $\dagger$} \\
\hline 0 & 131,052 & $5.42(1.81)$ & $5.41-5.43$ \\
\hline 1 & 106,703 & $5.17(1.78)$ & $5.16-5.18$ \\
\hline 2 & 50,351 & $5.01(1.81)$ & $4.99-5.03$ \\
\hline 3 & 18,852 & $4.89(1.83)$ & $4.86-4.92$ \\
\hline $4+$ & 10,803 & $4.67(1.86) \ddagger$ & $4.63-4.71$ \\
\hline Total & 317,761 & & \\
\hline \multicolumn{4}{|l|}{ Marital status $\ddagger$} \\
\hline Unmarried & 27,362 & $4.82(1.77)$ & $4.80-4.84$ \\
\hline Married & 290,399 & $5.25(1.82)$ & $5.24-5.26$ \\
\hline Total & 317,761 & & \\
\hline \multicolumn{4}{|c|}{ Maternal educational level\$ } \\
\hline Low & 82,881 & $4.47(1.73)$ & $4.46-4.48$ \\
\hline Medium & 203,161 & $5.34(1.75)$ & $5.33-5.35$ \\
\hline High & 31,719 & $6.36(1.66)$ & $6.34-6.38$ \\
\hline Total & 317,761 & & \\
\hline \multicolumn{4}{|l|}{ Year of birth $\ddagger$} \\
\hline 1967-1970 & 107,905 & $5.14(1.83)$ & $5.13-5.15$ \\
\hline 1971-1974 & 99,945 & $5.25(1.85)$ & $5.24-5.26$ \\
\hline $1975-1979$ & 109,911 & $5.26(1.76)$ & $5.25-5.27$ \\
\hline Total & 317,761 & & \\
\hline
\end{tabular}

Data from Medical Birth Registry of Norway, 1967-1979, linked with the Norwegian Conscripts Service, 1984-1999, and Statistics Norway, 19671998.

* Overall test for differences in mean intelligence test score between the categories of the listed birth characteristics (analysis of variance).

$\dagger$ Number of previous births, including stillbirths.

$\ddagger p<0.001$.

with a tendency toward lower scores in the upper categories (Fig. $1 B$ and $C$ ). The scores for preterm births were higher than for term births for birth weights $<3000 \mathrm{~g}$ and birth lengths $<50 \mathrm{~cm}$. For example, for birth weights $2000-2499 \mathrm{~g}$, mean score was 4.99 versus 4.84 , respectively, for preterm and term births $(p<0.0005)$. In general, the association between birth size and intellectual performance was weaker for preterm compared with term births.

Table 1 presents mean intelligence test scores at conscription stratified by potential confounding factors. Maternal age, maternal educational level, and year of birth were positively associated with intellectual performance, whereas there was a negative association with maternal parity and mother being unmarried. There was an almost linear increase in intelligence test score by increasing adult height within each level of maternal education (Fig. 2A), whereas the association between intellectual performance and BMI was curvilinear, with declining scores at BMIs above the normal range (Fig. 2B).

Table 2 shows the associations of gestational age and birth size with intelligence test score. The reference groups were chosen based on the observed modes in Figure 1. Mean scores consistently decreased by lower gestational ages in both unadjusted analyses and analyses adjusted for maternal age, 
Table 2. Mean intelligence test scores by gestational age, birth weight, and length

\begin{tabular}{|c|c|c|c|c|c|}
\hline & Birth characteristics & $n$ & $\begin{array}{l}\text { Mean values (SE) } \\
\text { unadjusted }\end{array}$ & $\begin{array}{c}\text { Mean values }(\mathrm{SE}) \dagger \\
\text { adjusted }\end{array}$ & $\begin{array}{c}\text { Mean values }(\mathrm{SE}) \ddagger \\
\text { adjusted }\end{array}$ \\
\hline \multirow[t]{7}{*}{ Study cohort§ } & & & \multicolumn{2}{|c|}{ Gestational age (wk) } & \\
\hline & Intercept & & $5.26(0.00)$ & $5.53(0.01)$ & $5.60(0.01)$ \\
\hline & $30-33$ & 2593 & $-0.38(0.04)$ & $-0.29(0.03)$ & $-0.26(0.03)$ \\
\hline & $34-36$ & 10,836 & $-0.17(0.02)$ & $-0.11(0.02)$ & $-0.10(0.02)$ \\
\hline & $37-38$ & 37,484 & $-0.10(0.01)$ & $-0.06(0.01)$ & $-0.06(0.01)$ \\
\hline & Unclassified & 10,671 & & & \\
\hline & Total & 317,761 & & & \\
\hline \multirow[t]{9}{*}{ Gestational age $\geq 37 \mathrm{wk}$} & & & \multicolumn{2}{|c|}{ Birth weight $(\mathrm{g})$} & \\
\hline & Intercept & & $5.36(0.01)$ & $5.61(0.01)$ & $5.63(0.01)$ \\
\hline & $\leq 1500$ & 42 & $-1.08(0.28)$ & $-0.88(0.26)$ & $-0.67(0.26)$ \\
\hline & $1500-1999$ & 366 & $-0.54(0.10)$ & $-0.57(0.09)$ & $-0.32(0.09)$ \\
\hline & $4000-4499$ & 52,484 & 0 (Reference) & 0 (Reference) & 0 (Reference) \\
\hline & $4500-4999$ & 10,934 & $-0.03(0.02)$ & $-0.01(0.02)$ & $-0.04(0.02)$ \\
\hline & $\geq 5000$ & 1527 & $-0.10(0.05)$ & $-0.07(0.04)$ & $-0.12(0.04)$ \\
\hline & Unclassified & 278 & & & \\
\hline & Total & 293,252 & & & \\
\hline \multirow[t]{7}{*}{ Gestational age $\geq 37$ wk } & & & \multicolumn{2}{|c|}{ Birth length $(\mathrm{cm})$} & \\
\hline & Intercept & & $5.39(0.01)$ & $5.63(0.02)$ & $5.61(0.02)$ \\
\hline & $\leq 43$ & 266 & $-0.78(0.11)$ & $-0.75(0.11)$ & $-0.40(0.11)$ \\
\hline & $44-45$ & 1342 & $-0.61(0.05)$ & $-0.54(0.05)$ & $-0.27(0.05)$ \\
\hline & $46-47$ & 8808 & $-0.46(0.02)$ & $-0.40(0.02)$ & $-0.17(0.02)$ \\
\hline & $48-49$ & 42,362 & $-0.33(0.01)$ & $-0.29(0.01)$ & $-0.11(0.01)$ \\
\hline & $50-51$ & 112,281 & $-0.18(0.01)$ & $-0.15(0.01)$ & $-0.04(0.01)$ \\
\hline
\end{tabular}

Data from the Medical Birth Registry of Norway, 1967-1979, linked with the Norwegian Conscripts Service, 1984-1999, and Statistics Norway, 1967-1998

$\dagger$ Analyses of variance. Adjusted for the following categorized factors: maternal age (years): $<20,20-24,25-29,30-34, \geq 35$; maternal education (years): $<11,11-14, \geq 14$; parity: 0,1+. Reference groups: maternal age, 25-29 years; maternal education, 11-14 years; parity, $1+$.

$\ddagger$ Analyses of variance. Adjusted for maternal age, maternal education, and parity as above, plus (height-179.9) and (height-179.9) (covariates) and body mass index $\left(\mathrm{kg} / \mathrm{m}^{2}\right)$ categorized as $<18.5,18.5-24.9$ (reference), 25.0-29.9, 30.0-39.9, and $>40.0$. Mean height (179.9 cm) was subtracted to achieve comparable constants.

$\S$ Conscripts with complete data on birth characteristics, intelligence test score, and maternal educational level.

parity, maternal educational level, adult height, and BMI. The effects on intellectual performance were strong for all factors in Table 2, both unadjusted and adjusted $(p<0.0005)$. Analyses of the association between birth size and intellectual performance were complicated by the strong interaction between birth weight or birth length and gestational age on intellectual performance $(p<0.0005$ for both, post hoc analysis), as described above. Thus, to separate the effects of growth retardation from immaturity, preterm births were excluded in analyses of the associations of birth weight and birth length with intellectual performance. Consequently, in Table 2 , the low birth weight or short length categories are most likely growth-restricted babies. In crude analyses, intelligence test score decreased by lower birth weights and shorter birth lengths. To evaluate the contribution of later growth to this association separately from that of social factors, we made two sets of adjustments. First, adjustment for maternal age, parity, and maternal educational level only slightly changed the estimated intelligence test scores. Next, further adjustment for adult height and BMI resulted in marked attenuation of the associations. Additional adjustment for year of birth and marital status did not change the results. The decline in scores observed in Figure 1 for the highest categories of birth weight, as well as gestational age, remained after adjustment.

There was no statistical evidence of interaction on intellectual performance between birth weight and adult height or birth length and adult height, either between birth size and BMI or between birth size and maternal education $(p>0.05$ for all).

Table 3 shows estimated regression coefficients $(\beta)$ and the proportions of variation $\left(R^{2}\right)$ in intellectual performance explained by birth size ( $z$ scores). Again, preterm births were excluded due to the strong interactions between gestational age and birth size (Fig. 2). In this context, $\beta$ represents the increase in intelligence by $1 \mathrm{SD}$ increase in birth weight or length. $\beta$ values for birth weight and birth length were 0.107 
Table 3. Multivariate linear regression analysis with estimated regression coefficients with SE and measure for explained variance $\left(R^{2}\right)$ of birth size measures on intelligence test score among 289,252 drafted males born at gestational age $\geq 37$ wk with complete information on all variables

\begin{tabular}{|c|c|c|}
\hline \multirow[b]{2}{*}{ Factors* } & \multicolumn{2}{|c|}{ Birth size } \\
\hline & $\begin{array}{l}\text { Regression } \\
\text { coefficients }(\beta) \\
\text { with SE }\end{array}$ & $R^{2}$ \\
\hline Birth weight & $0.107(0.003)$ & 0.003 \\
\hline Birth weight + maternal education $\dagger$ & $0.086(0.003)$ & 0.088 \\
\hline $\begin{array}{l}\text { Birth weight }+ \text { maternal education }+ \\
\text { maternal age }+ \text { parity }\end{array}$ & $0.102(0.003)$ & 0.109 \\
\hline $\begin{array}{l}\text { Birth weight }+ \text { maternal education }+ \\
\text { maternal age }+ \text { parity }+ \text { height }+ \\
\text { BMI }+\end{array}$ & $0.057(0.003)$ & 0.120 \\
\hline Birth length & $0.116(0.003)$ & 0.004 \\
\hline Birth length + maternal education & $0.097(0.003)$ & 0.089 \\
\hline $\begin{array}{l}\text { Birth length }+ \text { maternal education }+ \\
\text { maternal age }+ \text { parity }\end{array}$ & $0.101(0.003)$ & 0.109 \\
\hline $\begin{array}{l}\text { Birth length }+ \text { maternal education }+ \\
\text { maternal age }+ \text { parity }+ \text { height }+ \\
\text { BMI } \neq\end{array}$ & $0.041(0.003)$ & 0.120 \\
\hline
\end{tabular}

Data from Medical Birth Registry of Norway 1967-1979, linked with the Norwegian Conscripts Service 1984-1999, and Statistics Norway, 19671998.

* Gestational age-specific $\mathbf{z}$ scores (SDs above or below the mean) for birth weight and birth length (recorded in $\mathrm{g}$ and $\mathrm{cm}$, respectively). $z$ Scores for height (recorded in $\mathrm{cm}$ ) were calculated based on data from the study cohort.

$\dagger$ Maternal education categorized as $<11,11-14, \geq 14$ years. Reference group: 11-14 years (medium level).

$\ddagger$ Maternal age categorized as $<20,20-24,25-29,30-34, \geq 35$ years; parity (number of previous births, including stillbirths) categorized as $0,1+$; BMI $<18.5,18.5-24.9,25.0-29.9,30.0-39.9, \geq 40.0 \mathrm{~kg} / \mathrm{m}^{2}$. Reference groups: maternal age, 25-29 years; parity, 1+; BMI, 18.5-24.9.

$(\mathrm{SE}=0.003)$ and $0.116(\mathrm{SE}=0.003)$, respectively, but were slightly reduced after inclusion of maternal education in the model $[0.086(\mathrm{SE}=0.003)$ and $0.097(\mathrm{SE}=0.003)$, respectively]. However, after adding maternal age, parity, maternal education, adult height, and BMI to the model, the $\beta$ values were strongly reduced $[0.054(\mathrm{SE}=0.003)$ and $0.041(\mathrm{SE}=$ $0.003)$, respectively]. Further adjustment with height as quadratic term did not influence the regression coefficients. Unadjusted $\beta$ for adult height ( $1 \mathrm{SD})$ was $0.208(\mathrm{SE}=0.005)$ and remained unchanged when either birth weight or birth length were included in the model, but was reduced when further considering maternal age, parity, and maternal educational level (data not shown).

The overall $R^{2}$ of intellectual performance explained by either weight or length at birth was 0.003 or 0.004 , respectively (Table 3). Adding maternal age, parity, maternal education, adult height, and BMI increased $R^{2}$ to 0.120 for both. Thus, $12 \%$ of the variance in intellectual performance was explained by these factors in addition to birth size.

Table 4 shows the ORs for low intelligence test scores associated with birth characteristics, with adjustment for maternal age, parity, maternal educational level, adult height, and BMI. Compared with those born at 39-41 wk, infants born at gestational ages 26-29, 30-33, and 34-36 wk, had an OR for low score of 2.19 (95\% CI: 1.77-2.70), 1.44 (95\% CI: $1.31-$
1.58), and 1.21 (95\% CI: 1.15-1.27), respectively. In addition, the $\mathrm{OR}$ was increased among postterm infants $(\mathrm{OR}=1.09$; 95\% CI: 1.06-1.12). These ORs were similarly elevated after adjustment. Table 4 also shows the ORs for low score associated with $z$ scores for birth weight (excluding preterm births). The crude ORs ranged from 1.75 (95\% CI: 1.53-2.02) for $z$ scores $\leq-3.00$ to 1.17 (95\% CI: $1.14-1.20$ ) for $z$ scores between -1.99 and -0.50 . These ORs were reduced after adjustment for maternal age, parity, and maternal educational level but were still increased even after further adjustment for current body size. Large infants ( $z$ score for birth weight $>3.00)$ had a slightly elevated risk of low score $(1.22 ; 95 \%$ CI: $1.00-1.48)$ when all factors were included in the model. The results for $z$ scores for birth length were essentially similar to that observed for birth weight.

\section{DISCUSSION}

Birth weight, birth length, and gestational age are associated with intellectual performance, even after adjustment for social factors and adult body size; however, the associations are weak.

The strengths of this study are the large sample size, the population-based design, and the high degree of follow-up; by linking national registers, $94 \%$ of the birth cohort was traced until age $18 \mathrm{y}$. However, infants born preterm or with low birth weight were more likely lost to follow-up and not drafted because the proportions of infant deaths and disability were higher than among term and normal weight infants (21). Also conscripts who had missing data on intellectual performance had slightly lower birth weight (3559 g), birth length (50.9 $\mathrm{cm}$ ), and gestational age (39.8 wk) compared with the study cohort. Hence, a selection bias toward a healthy population might be possible. This may affect the validity regarding intellectual performance. For preterm and low birth weight infants, not attending the draft board may be associated with lower intellectual performance, implying that the observed mean scores would be higher than the true values. Thus, if data on those lost to follow-up had been available, the observed associations probably would have been strengthened. However, despite loss to follow-up, we observed low scores for the lowest gestational age and birth size categories, as expected according to previous studies using somewhat different types of data and design $(6-11,13,19)$. Furthermore, our data compare with other Scandinavian studies using military draft data from practically the same time period and including males only $(6,7,19)$. Still, the restriction to male participants may limit the external validity of our findings.

In our study, data on gestational age and birth length were available, thereby providing a better measure of prenatal growth than indicated by birth weight alone. Gestational age in the Medical Birth Registry was based on self-reported information about the last menstrual period because ultrasound dating was not recorded in this cohort of births. Although infants with $z$ scores for birth weight (or birth length) by gestational age outside $4 \mathrm{SD}$ were excluded in the linear models (34), misclassification is still likely. 
Table 4. ORs (95\% CI) of intelligence test scores $\leq 3$ among male conscripts by birth characteristics

\begin{tabular}{|c|c|c|c|c|c|c|c|}
\hline & Birth characteristics & No. $1-9$ & No. $\leq 3$ & $\%<3$ & $\begin{array}{c}\text { Unadjusted } \\
\text { OR (95\% CI) }\end{array}$ & $\begin{array}{c}\text { Adjusted* } \\
\text { OR }(95 \% \mathrm{CI})\end{array}$ & $\begin{array}{c}\text { Adjusted } \dagger \\
\text { OR }(95 \% \text { CI) }\end{array}$ \\
\hline \multirow[t]{6}{*}{ Study cohort $\$$} & Gestational age, y & & & & & & \\
\hline & $26-29$ & 409 & 123 & 30.1 & $2.19(1.77-2.70)$ & $1.86(1.49-2.31)$ & $1.93(1.55-2.41)$ \\
\hline & $34-36$ & 10,836 & 2084 & 19.2 & $1.21(1.15-1.27)$ & $1.06(1.01-1.12)$ & $1.14(1.08-1.20)$ \\
\hline & $37-38$ & 37,484 & 6849 & 18.3 & $1.14(1.11-1.17)$ & $1.02(0.99-1.06)$ & $1.10(1.06-1.13)$ \\
\hline & $39-41$ & 209,191 & 34,382 & 16.4 & 1.00 (Reference) & 1.00 (Reference) & 1.00 (Reference) \\
\hline & Total & 317,761 & 52,242 & 17.0 & & & \\
\hline \multirow[t]{6}{*}{ Gestational age $\geq 37$ wk } & $z$ score $\S$ for birth weight & & & & & & \\
\hline & $\leq-3.00$ & 1056 & 266 & 25.2 & $1.75(1.53-2.02)$ & $1.67(1.32-2.12)$ & $1.46(1.26-1.69)$ \\
\hline & $-2.99,-2.00$ & 7821 & 1777 & 22.7 & $1.53(1.45-1.62)$ & $1.43(1.17-1.74)$ & $1.32(1.25-1.40)$ \\
\hline & $-1.99,-0.50$ & 96,451 & 17,690 & 18.3 & $1.17(1.14-1.20)$ & $1.09(0.90-1.32)$ & $1.09(1.07-1.12)$ \\
\hline & $-0.49,0.50$ & 113,662 & 18,306 & 16.1 & 1.00 (Reference) & 1.00 (Reference) & 1.00 (Reference) \\
\hline & Total & 293,252 & 49,412 & 16.8 & & & \\
\hline \multirow[t]{10}{*}{ Gestational age $\geq 37 \mathrm{wk}$} & $z$ score for birth length & & & & & & \\
\hline & $\leq-3.00$ & 662 & 168 & 25.4 & $1.72(1.44-2.05)$ & $1.85(1.40-2.45)$ & $1.37(1.14-1.65)$ \\
\hline & $-2.99,-2.00$ & 4430 & 1031 & 23.3 & $1.53(1.43-1.65)$ & $1.58(1.26-1.99)$ & $1.23(1.14-1.33)$ \\
\hline & $-1.99,-0.50$ & 73,643 & 13,906 & 18.9 & $1.18(1.15-1.21)$ & $1.24(1.00-1.53)$ & $1.07(1.04-1.10)$ \\
\hline & $-0.49,0.50$ & 119,884 & 19,806 & 16.5 & 1.00 (Reference) & 1.00 (Reference) & 1.00 (Reference) \\
\hline & $0.51,2.00$ & 82,771 & 12,649 & 15.3 & $0.91(0.89-0.93)$ & $1.06(0.85-1.31)$ & $0.99(0.97-1.02)$ \\
\hline & $2.01,3.00$ & 8261 & 1264 & 16.3 & $0.91(0.86-0.97)$ & $0.97(0.78-1.20)$ & $1.09(1.02-1.16)$ \\
\hline & $>3.00$ & 647 & 104 & 16.1 & $0.97(0.78-1.19)$ & $0.97(0.78-1.22)$ & $1.18(0.95-1.47)$ \\
\hline & Unclassified & 2954 & & & & & \\
\hline & Total & 293,252 & 48,928 & 16.7 & & & \\
\hline
\end{tabular}

Data from the Medical Birth Registry of Norway, 1967-1979, linked with the Norwegian Conscripts Service, 1984-1999, and Statistics Norway, 1967-1998.

* Adjusted for the following categorized factors: maternal age (years): $<20,20-24,25-29,30-34,>35$; maternal education (years): <11, 11-14, $\geq 14$; parity: $0,1+$. Reference groups: maternal age, 25-29 years; maternal education, 11-14 years; parity, $1+$.

$\dagger$ Adjusted for maternal age, maternal education, and parity as above plus (height-179.9) and (height-179.9) ${ }^{2}$ (covariates) and body mass index (kg/m ${ }^{2}$ ) categorized as $<18.5,18.5-24.9$ (reference), 25.0-29.9, 30.0-39.9, and $\geq 40.0$. Mean height $(179.9 \mathrm{~cm})$ was subtracted to achieve comparable constants.

$\mp$ Conscripts with complete data on birth characteristics, intelligence test score, and maternal educational level.

$\S$ Gestational age-specific $z$ scores (SDs above or below the mean) for birth weight and birth length (recorded in $\mathrm{g}$ and $\mathrm{cm}$, respectively).

The intelligence test used in our study correlates $r=0.73$ with the Wechsler Adult Intelligence Scale, which is somewhat lower than in the study by Sørensen et al. $(r=0.8)(7)$. Still, to assess intellectual ability and suitability for military service, this standardized test has been considered appropriate and applied unchanged as part of the draft board examination, compulsory for every able young man in Norway since the early 1950 s.

More direct measures of maternal intelligence and socioeconomic status, important predictors of offspring's intellec-
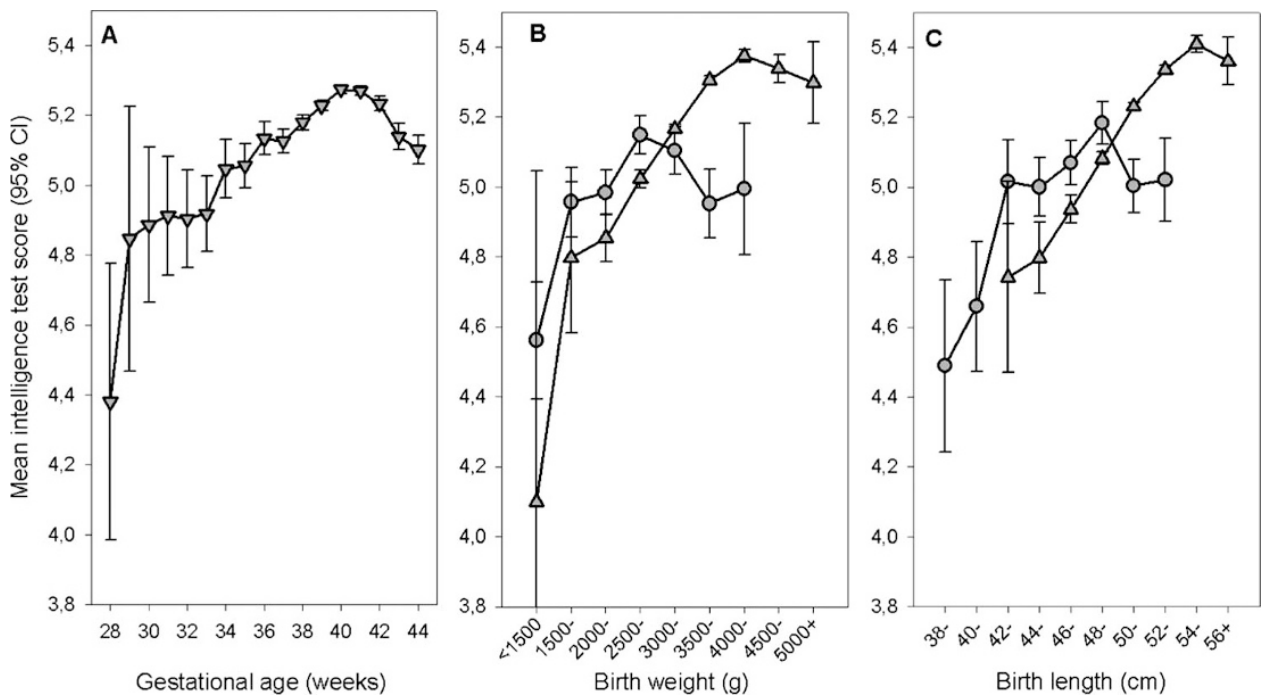

Figure 1. Mean intelligence test score with $95 \%$ CIs by gestational age $(A)$, birth weight $(B)$, and birth length $(C)$ stratified by gestational age; 317,761 male infants, Medical Birth Registry of Norway, 19671979, linked with the Norwegian Conscripts Service, 1984-1999. Term = $37-41$ wk gestational age, preterm $=<37$ wk gestational age. $\diamond$, preterm; $\boldsymbol{\nabla}$, term. 


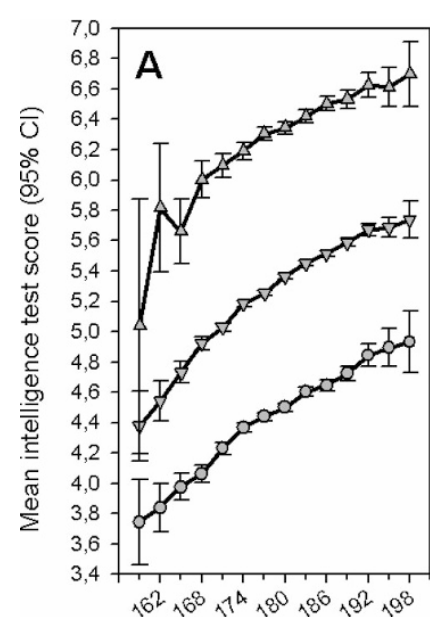

Height $(\mathrm{cm})$

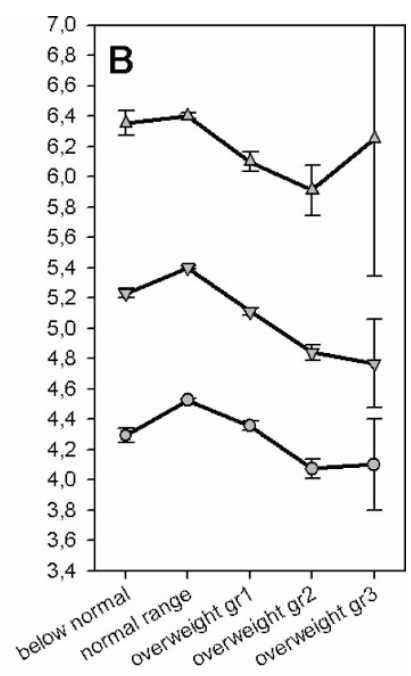

Body mass index $(\mathrm{kg} / \mathrm{m} 2)$

Figure 2. Mean intelligence test scores with $95 \%$ CIs among 317,761 drafted males, by height $(A)$ and BMI $(B)$ at conscription, stratified by three levels of maternal education. The Norwegian Conscripts Service (1984-1999) linked

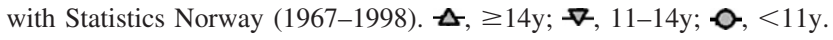

tual outcomes $(13,14)$, were unavailable. Although maternal educational attainment is a strong proxy measure of intelligence $(2,4)$, residual confounding may still be present. Maternal education also served as an indicator of socioeconomic status, together with maternal age, marital status, and parity. In general, education is found to be more strongly and consistently associated with health and disease than is income or occupation (36). Still, residual confounding by socioeconomic status is likely. Unfortunately, neither data on postnatal factors, such as nutrition, psychological stimulation, childhood illness, and lifestyle, nor data for evaluating the possible influence of stress hormones or growth factors as suggested by other researchers $(9,10,18)$, were available in our registries.

The association of birth size with intellectual performance was weak, as summarized in a recent review (18). Most previous studies on the association between birth weight and intellectual performance do not consider the contribution of current size $(7-9,11,14,16,17)$, whereas others have shown an effect of later growth in terms of height $(6,10,25)$. Some studies did not control for maternal education $(6-8,12,25)$ or gestational age $(9,10)$. Although it was weak, we observed a prenatal influence on intellectual performance independent of the contribution of social factors and adult size, consistent with Richards et al. (10), but in contrast to Pearce et al. (25). This may reflect biological processes occurring during fetal growth that affect adult intelligence, as suggested by the fetal programming hypothesis (37). Conversely, genetic or environmental factors may affect prenatal growth as well as later growth and intelligence, without going through the programming pathway.

It has been suggested that postnatal growth has a greater influence on intelligence than fetal growth (25). Also, Martyn et al. (38) noted that prenatal growth seems to be less important than genetic factors and environmental influences in postnatal life in determining adult cognitive performance. Lucas et al. (20) have suggested that adult size must be taken

into consideration when examining early life exposures and outcomes in later life. However, there is some discussion about whether adjusting for variables that may be on the causal pathway is appropriate $(39,40)$. We found that the association between birth size and intellectual performance was attenuated after adjustment for adult size, while the influence of adult height on intellectual performance was almost unchanged. Our interpretation is that adult height dominated the effects of birth size, slightly more for birth length than for birth weight. Neither adult weight nor BMI had a similar attenuating effect. Birth size and adult height are measures of growth that are strongly correlated (21). In contrast, birth size is less correlated with maternal education (8). However, adjustment for current body size may be wrong. For example, if fetal growth, including brain growth, is impaired and insulin resistance is induced to prepare for shortage of food, then adult obesity may be an epiphenomenon to the association between birth weight and intellectual performance, and adjusting for current body size may be misleading. In our study, if adult height (and BMI) is on the causal pathway between birth weight and intellectual performance, adjustment for adult height may introduce a bias because adult height and intellectual performance may have unmeasured common causal factors (e.g. childhood nutrition). Such a bias may lead to an underestimation of the association between birth size and intellectual performance. Hence, the strong influence of adult height on the association between birth size and intellectual performance could be explained by overadjusting for factors on the causal pathway. Conversely, these factors are strongly linked to maternal education (Fig. 2); thus, adjusting for maternal education will probably close this backdoor path and the assumed bias will be reduced.

Only a small part of the variation in intellectual performance was due to birth size $\left(R^{2}=0.3 \%-0.4 \%\right)$. Even the full model (including birth size, adult size, and social factors) explained only $12 \%$, and most of the variation was explained by maternal education $\left(R^{2}=8.4 \%\right)$. Similar results have been reported in previous studies $(8,14,24)$. Maternal education appeared to be an important confounder when evaluating prenatal influences on offspring's intellectual performance, possibly by inequalities in social conditions, as well as by the influence of maternal genes.

Gestational age is relevant in the interpretation of birth weight as an indicator of prenatal growth. Consistent with a recent Swedish study (19), we observed an interaction between birth size and gestational age on intellectual performance (Fig. 1). In our study, approximately $40 \%$ of the preterm infants had a birth weight $<2500 \mathrm{~g}$ compared with $1 \%$ of term infants. For infants with birth weight 2000-2499 $\mathrm{g}$, those born preterm actually performed better than those born at term. This result may seem surprising, but these births represent a low birth weight in term births, but not in preterm births. The study by Bergvall et al. (19) seems to provide similar results, although they do not compare term and preterm births directly. It has been suggested that the importance of birth weight on neurodevelopmental outcome is lower than that of gestational age (19). The interpretation of our finding may be that compared with term births, birth size in preterm 
infants is less predictive of the intellectual potential. In preterm infants, attained birth size may have been influenced by complications in pregnancy leading to preterm birth, whereas at term, small size is more likely to reflect growth retardation.

We found a decline in scores among postterm births, as observed in the study by Record et al. (26). Also, there was a slight decrease in intelligence test score at the highest birth weights, as observed in two previous studies $(7,8)$. These results are a supplement to previous studies, but must be interpreted carefully in clinical settings and cannot be applied to the history of any one child.

Although these historical data do not allow us to speculate on the biological pathways, our conclusion is that the positive association between birth size and intellectual performance is influenced by later growth, but still intellectual performance is dominated by maternal education.

Acknowledgments. The authors thank John Ivar Brevik and his staff at the Norwegian Conscripts Service for help in collecting the data from the draft examination, Ola Thune for technical assistance, and Grethe S. Tell, Guri Rørtveit, David Batty, and Kari Melve for helpful comments on previous versions of the manuscript.

\section{REFERENCES}

1. Osler M, Andersen AM, Due P, Lund R, Damsgaard MT, Holstein BE 2003 Socioeconomic position in early life, birth weight, childhood cognitive function, and adult mortality. A longitudinal study of Danish men born in 1953. J Epidemiol Community Health 57:681-686

2. Batty GD, Deary IJ 2004 Early life intelligence and adult health. BMJ 329:585-586

3. Kuh D, Richards M, Hardy R, Butterworth S, Wadsworth ME 2004 Childhood cognitive ability and deaths up until middle age: a post-war birth cohort study. Int J Epidemiol 33:408-413

4. Osler M, Batty GD 2004 Commentary: influence of early life intelligence test performance on later health: do lower scoring children become less healthy adults? Int J Epidemiol 33:414-415

5. Lucas A 1991 Programming by early nutrition in man. Ciba Found Symp 156:38-50

6. Lundgren EM, Cnattingius S, Jonsson B, Tuvemo T 2001 Intellectual and psychological performance in males born small for gestational age with and without catch-up growth. Pediatr Res 50:91-96

7. Sørensen HT, Sabroe S, Olsen J, Rothman KJ, Gillman MW, Fischer P 1997 Birth weight and cognitive function in young adult life: historical cohort study. BMJ 315:401-403

8. Shenkin SD, Starr JM, Pattie A, Rush MA, Whalley LJ, Deary IJ 2001 Birth weight and cognitive function at age 11 years: the Scottish Mental Survey 1932. Arch Dis Child 85:189-196

9. Richards M, Hardy R, Kuh D, Wadsworth ME 2001 Birth weight and cognitive function in the British 1946 birth cohort: longitudinal population based study. BMJ 322:199-203

10. Richards M, Hardy R, Kuh D, Wadsworth ME 2002 Birthweight, postnatal growth and cognitive function in a national UK birth cohort. Int J Epidemiol 31:342-348

11. Matte TD, Bresnahan M, Begg MD, Susser E 2001 Influence of variation in birth weight within normal range and within sibships on IQ at age 7 years: cohort study. BMJ 323:310-314

12. Lundgren EM, Cnattingius S, Jonsson B, Tuvemo T 2003 Intellectual and psychological performance in males born small for gestational age. Horm Res 59:139-141
13. Hack M, Flannery DJ, Schluchter M, Cartar L, Borawski E, Klein N 2002 Outcomes in young adulthood for very-low-birth-weight infants. N Engl J Med 346:149-157

14. Jefferis BJ, Power C, Hertzman C 2002 Birth weight, childhood socioeconomic environment, and cognitive development in the 1958 British birth cohort study. BMJ 325:305

15. Doyle LW, Casalaz D 2001 Outcome at 14 years of extremely low birthweight infants: a regional study. Arch Dis Child Fetal Neonatal Ed 85:F159-F164

16. Goldenberg RL, DuBard MB, Cliver SP, Nelson KG, Blankson K, Ramey SL, Herman A 1996 Pregnancy outcome and intelligence at age five years. Am J Obstet Gynecol 175:1511-1515

17. Paz I, Laor A, Gale R, Harlap S, Stevenson DK, Seidman DS 2001 Term infants with fetal growth restriction are not at increased risk for low intelligence scores at age 17 years. J Pediatr 138:87-91

18. Shenkin SD, Starr JM, Deary IJ 2004 Birth weight and cognitive ability in childhood: a systematic review. Psychol Bull 130:989-1013

19. Bergvall N, Iliadou A, Johansson S, Tuvemo T, Cnattingius S 2006 Risks for low intellectual performance related to being born small for gestational age are modified by gestational age. Pediatrics 117:e460-e467

20. Lucas A, Fewtrell MS, Cole TJ 1999 Fetal origins of adult disease-the hypothesis revisited. BMJ 319:245-249

21. Eide MG, Øyen N, Skjærven R, Nilsen ST, Bjerkedal T, Tell GS 2005 Size at birth and gestational age as predictors of adult height and weight. Epidemiology 16:175181

22. Teasdale TW, Owen DR, Sørensen TI 1991 Intelligence and educational level in adult males at the extremes of stature. Hum Biol 63:19-30

23. Tuvemo T, Jonsson B, Persson I 1999 Intellectual and physical performance and morbidity in relation to height in a cohort of 18-year-old Swedish conscripts. Horm Res 52:186-191

24. Downie AB, Mulligan J, Stratford RJ, Betts PR, Voss LD 1997 Are short normal children at a disadvantage? The Wessex growth study. BMJ 314:97-100

25. Pearce MS, Deary IJ, Young AH, Parker L 2005 Growth in early life and childhood IQ at age 11 years: the Newcastle Thousand Families Study. Int J Epidemiol 34:673-677

26. Record RG, McKeown T, Edwards JH 1969 The relation of measured intelligence to birth weight and duration of gestation. Ann Hum Genet 33:71-79

27. Irgens LM 2000 The Medical Birth Registry of Norway. Epidemiological research and surveillance throughout 30 years. Acta Obstet Gynecol Scand 79:435-439

28. Sundet JM, Barlaug DG, Torjussen TM 2004 The end of the Flynn effect?: a study of secular trends in mean intelligence test scores of Norwegian conscripts during half a century. Intelligence 32:349-362

29. Official Statistics Norway 2000 Norwegian Standard Classification of Education. Available at: http://www.ssb.no/emner/04/90/nos_c617/ (accessed June 13, 2007)

30. The Royal Ministry of Health and Social Affairs January 2000; The Norwegian Social Insurance Scheme. Available at: http://www.regjeringen.no/nb/ dokumentarkiv/Regjeringen-Jagland/231700/231701/231702/the_norwegian social_insurance.html?id=231707 (accessed on June 13, 2007)

31. Sundet JM, Tambs K, Magnus P, Berg K 1988 On the question of secular trends in the heritability of IQ test scores: a study of Norwegian twins. Intelligence 12:47-59

32. Tambs K, Sundet JM, Magnus P, Berg K 1989 Genetic and environmental contributions to the covariance between occupational status, educational attainment, and IQ: a study of twins. Behav Genet 19:209-222

33. Eide MG, Øyen N, Skjærven R, Irgens LM, Bjerkedal T, Nilsen ST 2005 Breech delivery and intelligence: a population-based study of 8,738 breech infants. Obstet Gynecol 105:4-11

34. Skjærven R, Gjessing HK, Bakketeig LS 2000 Birthweight by gestational age in Norway. Acta Obstet Gynecol Scand 79:440-449

35. World Health Organization 1998 Preventing and Managing the Global Epidemic. Report of a WHO Consultation on Obesity. June 3-5 1997. WHO, Geneva

36. Winkleby MA, Jatulis DE, Frank E, Fortmann SP 1992 Socioeconomic status and health: how education, income, and occupation contribute to risk factors for cardiovascular disease. Am J Public Health 82:816-820

37. Barker DJ 1994 Mothers, Babies, and Disease in Later Life. BMJ Publishing Group, London

38. Martyn CN, Gale CR, Sayer AA, Fall C 1996 Growth in utero and cognitive function in adult life: follow up study of people born between 1920 and 1943. BMJ 312:1393-1396

39. Greenland S, Pearl J, Robins JM 1999 Causal diagrams for epidemiologic research. Epidemiology 10:37-48

40. Hernandez-Diaz S, Schisterman EF, Hernan MA 2006 The birth weight "paradox" uncovered? Am J Epidemiol 164:1115-1120 